Tong et al., Okmen and Turkcan Afr J Tradit Complement Altern Med. (2014) 11(1):109-115

CHINESE HERB-RESISTANCE AND ADHERENCE TO HUMAN UROEPITHELIAL CELLS OF UROPATHOGENIC ESCHERICHIA COLI

\title{
YanQing *Tong, $\quad{ }^{1}$ Bing Xin and ${ }^{1}$ Ying Chi
}

Department of Nephrology, The First Affiliated Hospital to Changchun University of Chinese Medicine, Changchun city, Jilin province, China. 1Department of Microbiology, The First Affiliated Hospital to Changchun University of Chinese Medicine, Changchun city, Jilin province, China. ${ }^{1}$ Department of Microbiology, The First Affiliated Hospital to Changchun University of Chinese Medicine, Changchun city, Jilin province, China.

*Email: tongyanqing@yahoo.com

\section{Abstract}

Background: In order to define the virulence factors between Chinese herb-resistant uropathogenic E. coli and susceptible strains, the UPEC isolates were classified into two groups according to its resistance to Chinese herbs.

Materials and Methods: The susceptibility profile of strains was determined by disk diffusion method. PCR systems were used to detect genes encoding papC, Aer, hly and cnf1. Isolated human urothelial cells were incubated in vitro and investigated with light microscope immunohistochemistry. Adhesion of E. coli to urothelial cells was studied in vitro.

Results: The results showed that, among the 105 UPEC isolates, 18 were resistant to the herbal concoction. Cnf1 and papC occurred in $\geqslant 66.7 \%$, of herb-resistant isolates, while, hly and Aer occurred in $22.2 \%$ and $27.8 \%$ of strains respectively. Only one gene (Cnf1) occurred in $>40 \%$, of Herb-susceptible isolates. Other genes were also found in susceptible isolates: papC (20.7\%), hly (11.5\%), and Aer (6.9\%). Light microscopy and immunochemical investigations demonstrated the normal pelvic transitional epithelial cells cultured. The adherence of strains in both groups increased in 30 min., and reached its peak at 60, (Susceptible E. coli) or 120 min., (Resistant E. coli). The adhesion of the susceptible bacteria to human uroepithelial cells was significantly lower compared with that of the resistant E. coli $(\mathrm{p}<0.05)$.

Conclusion: These findings revealed that, Chinese herb-resistant uropathogenic E. coli isolates that are hemolytic, and have Aer, papC, hly, Cnf1 genes are more able to be uropathogenic and adherent.

Key words: Escherichia coli; Adherence; Virulence genes; Human uroepithelial cells; Chinese herb-resistance.

\section{Introduction}

Escherichia coli (E. coli) is the principal cause of urinary tract infections (UTIs) in both community, and hospital settings in China. Most UTIs are due to uropathogenic E. coli (UPEC) infections. As one of the variety of virulent factors, the adhesion of E. coli to uroepithelial cells is the first step in the development of UTIs (Beachey, 1981), enabling them to colonize the host.

Herbal medicine has been used in the treatment of UTIs over the years. Herbal formulation used in this study was proved to have anti-microbial and anti-adherent effect, in our previous research (Tong et al., 2011a; Tong et al., 2011b). But clinical isolates of uropathogenic E. coli resistance to this herbal formulation have been isolated. In order to define the virulence factors, and adherent ability between Chinese herb-resistant uropathogenic E. coli and susceptible strains in China, we compared four specific virulence genes expression and the bacterial adherence to human uroepithelial cells between these isolates.

\section{Methods}

\section{Bacterial strains}

A total of 105 E. coli isolates from humans with community-acquired UTIs were used in this study. Isolation of E. coli strains was performed according to standard laboratory protocols and $E$. coli were isolated from, $>10^{5}$ cfu., of a uropathogen per milliliters of midstream 


\section{http://dx.doi.org/10.4314/ajtcam.v11i1.16}

urine culture. After isolation, the bacteria were kept frozen at, $-70{ }^{\circ} \mathrm{C}$ after the addition of $20 \%(\mathrm{v} / \mathrm{v})$ glycerol and they were not sub-cultured more than twice before the investigation.

\section{Chinese herbs and susceptibility test}

The Chinese herbs were prepared by the following ratio: Tong Cao (Medulla Tetrapanacis), 4 : Hua Shi (Talcum), 20 : Chi Shao (Radix Paeoniae Rubrae), 20 : Xiao Hui Xiang (Fructus Foeniculi Vulgaris,) 30 : Rou Gui (Cortex Cinnamomi), 30 : Li Zhi He (Semen Litchi), 30 : Tian Kui Zi (Radix Semiaquilegiae), 30 : Zi Hua Di Ding (Herba cum Rd Violae Yedoensitis), 30 : Qu Mai (Herba Dianthi), 40 : Ma Chi Xian (Herba Portulacae), 60 : Pu Gong Ying (Herba taraxaci), 60. The eleven crude drugs were mixed in $800 \mathrm{ml}$ water $\left(100{ }^{\circ} \mathrm{C}\right.$ for $30 \mathrm{~min}$. twice), leaving $100 \mathrm{ml}$ liquor after decanting the mixture. The liquor was centrifuged, filtered and sterilized with the solution of $0.5 \mathrm{~g} / \mathrm{ml}$ as the drug concentration. Standard disc diffusion methodology (Maidment et al., 2006), was used to test the concoction against E. coli strains. The minimal inhibitory concentration (MIC), of herbal solution for susceptible E. coli was determined as follows: Starting with the $0.5 \mathrm{~g} / \mathrm{ml}$ concentration, seven serial dilutions were prepared in LB agar $(0.5 \mathrm{~g} / \mathrm{ml}, 0.2 \mathrm{~g} / \mathrm{ml}, 0.1 \mathrm{~g} / \mathrm{ml}, 0.05 \mathrm{~g} / \mathrm{ml}, 0.025 \mathrm{~g} / \mathrm{ml}, 0.0125 \mathrm{~g} / \mathrm{ml}$, and $0.0 \mathrm{~g} / \mathrm{ml})$. These concentrations were inoculated with bacterial strain. The MIC was the lowest concentration of herbal solution that prevented obvious turbidity after incubation for $18 \mathrm{hr}$ at $37^{\circ} \mathrm{C}$.

\section{Hemolysis determination}

UPEC isolates were assessed for hemolysis activity on blood agar plates (supplemented with 5\% sheep blood), using standard methods (Maidment et al., 2006).

\section{Virulence genotyping}

UPEC strains were investigated for 4, virulence-related genes by single PCR essays, as previously described (Forbes et al., 1998; Johnson et al., 2000). Targeted genes and their primer sequence for the amplification procedures are given in Table 1. The amplified products were visualized by standard gel electrophoresis of $15 \mu \mathrm{l}$ of the final reaction mixture in $1.0 \%$ agarose gels in Triacetate/EDTA (TAE) buffer at $5 \mathrm{~V}$ $\mathrm{cm}^{-1}$. The gels were stained with ethidium bromide $\left(0.5 \mu \mathrm{g} \mathrm{ml}^{-1}\right)$ for $2 \mathrm{~min}$, washed in distilled water, analyzed under UV light (300 $\left.\mathrm{nm}\right)$, and photographed. DNA Ladder $100 \mathrm{bp}$ was used as molecular size marker. All amplification procedures were repeated three times.

\section{Tissues}

The collection of surgical specimens was approved by the relevant Local Research Ethics Committees and had full patient consent. Ureter specimens obtained at the time of radical nephrectomy for renal cell carcinoma (a Chinese, male, age 56 years). Urothelial tissue samples were obtained at surgery. Tissue samples were transported at room temperature from surgery in Hanks' balanced salt solution (Shanghai Biocolor Bio-Science \& Technology Company, China), containing 10mM HEPES, pH 7.6 and 20 kallikrein-inhibiting units (KIU)/ml of aprotinin (Shanghai Biocolor Bio-Science \& Technology Company, China). The specimen was trimmed to remove any serosa, fat, or debris and dissected into $1-\mathrm{cm}^{2}$ pieces. The sample was placed into HBSS, containing $10 \mathrm{mM}$ HEPES, pH 7.6, $20 \mathrm{KIU} / \mathrm{ml}$ Trasylol, and 0.1\% (wt/vol.), EDTA and incubated at $4{ }^{\circ} \mathrm{C}$ overnight to release urothelial cell sheets.

\section{Cell culture}

The isolated urothelial cells were incubated in vitro as previously described (Southgate et al., 1994; Southgate et al., 2002). NHU cells were maintained in keratinocyte serum-free medium (KSFM), containing recombinant epidermal growth factor and bovine pituitary extract at the manufacturer's recommended concentrations (Invitrogen, Paisley, UK) and supplemented with $30 \mathrm{ng} / \mathrm{ml}$ cholera toxin to improve cell plating and attachment (Hutton et al,.1993). KSFM fully supplemented with the aforementioned factors will be referred to as KSFM complete (KSFMc). The cultures were maintained at $37{ }^{\circ} \mathrm{C}$ in a humidified atmosphere of $5 \% \mathrm{CO}_{2}$ in air. The medium was replaced every $24 \mathrm{~h}$. Sections were investigated by light microscopy at $\times 400$ magnification at day $5,10,15$ and 20 . 
http://dx.doi.org/10.4314/ajtcam.v11i1.16

Light microscope immunohistochemistry

The seeded samples were investigated with immune histo-chemical methods at day 20 . The samples were treated with $1 \% \mathrm{H}_{2} \mathrm{O}_{2}$ for 5 min, washed with 0.1 M PBS and pre-incubated for 20 min., at room temperature with $0.1 \mathrm{M} \mathrm{PBS} \mathrm{(pH} \mathrm{7.4)} \mathrm{added} \mathrm{with} \mathrm{3 \%} \mathrm{normal} \mathrm{goat} \mathrm{serum}$ (NGS) and $0.5 \%$ Triton X-100. Then the samples were incubated in the primary antibody. The rabbit polyclonal antibody, which was raised in the rat against 21, amino acid peptide corresponding to the C-terminus of the rat capsaicin receptor protein (Zhongshan Goldenbridge Biotechnology Co. Ltd, China), was used at dilution 1:2000 in 0.1 M PBS (pH 7.4) added with 1.5\% NGS and 0.5\% Triton X-100. The antibody was applied overnight at $4{ }^{\mathrm{O}} \mathrm{C}$. This was followed by incubation with the biotinylated secondary antibody (dilution 1:100) for 1hr, at room temperature, rinsing in PBS, and by incubation with the avidin-biotin-complex (Zhongshan Goldenbridge Biotechnology Co. Ltd, China), for 30 min. Immuno-reactivity was detected at room temperature by addition of 3,3'-diaminobenzidine (Zhongshan Goldenbridge Biotechnology Co. Ltd, China), as a substrate, for 5-6 min. After washing in PBS containing 3\% NGS and 0.5\% Triton X-100, all samples were incubated with the primary antisera in moist chambers.

All the samples were counterstained with haematoxylin for nuclei labelling.

\section{In vitro adhesion of $\mathbf{E}$. coli to human urothelial cells}

$5 \mathrm{ml}$ of the bacterial suspension was added to a Leighton tube containing a cover slip with attached urothelial cells, and incubated for 1 hr, with gentle shaking at $37^{\circ} \mathrm{C}$. The cover slip was removed from the Leighton tube and washed twice with PBS to remove bacteria that had not adhered. The urothelial cells were fixed for 15 min., in methanol, washed twice again with PBS, and stained for 20 min., with $30 \%$ filtered Giemsa stain (Giemsas-L6sung; Merck, Darmstadt, Germany). After two washings with distilled water, the cover slip was dried in the air and mounted upside down on a glass slide. To determine the changes of adherence by herbal solution, the assay was carried out in the presence of herbal solution (MIC). Adherence was examined with a light microscope at $\times 400$, magnification. 100 , urothelial cells were selected randomly. The number of cells with bacterial adhesion and total number of adherent bacteria were counted. The adherence index and adherence ratio were calculated at time of $15,30,60,120$ and $180 \mathrm{~min}$ :

Adherence index $=$ number of adherent bacteria/100;

Adherence ratio $(\%)=($ number of cells with bacterial adhesion $/ 100) \times 100 \%$.

Table 1: Primers used for the amplification study

\begin{tabular}{|c|c|c|}
\hline Gene & Amplicon size (bp) & Primer sequence \\
\hline \multirow[t]{2}{*}{ Aer } & 209 & 5' end: 5'-CCAAGGGGTCTGTGGCGACA-3' \\
\hline & & 3' end: 5'-TTTCACCGGTAACAGGATTG-3' \\
\hline \multirow[t]{2}{*}{ papC } & 328 & 5' end: 5'-GACGGCTGTACTGCAGGGTGTGGCG-3' \\
\hline & & 3' end: 5'-ATATCCTTTCTGCAGGGATGCAATA-3' \\
\hline \multirow[t]{2}{*}{ hly } & 1177 & 5' end: 5'-AACAAGGATAAGCACTGTTCTGGCT-3' \\
\hline & & 3' end: 5'-ACCATATAAGCGGTCATTCCCGTCA-3' \\
\hline \multirow[t]{2}{*}{ Cnf1 } & 498 & 5' end: 5'-AAGATGGAGTTTCCTATGCAGGAG-3' \\
\hline & & 3' end: 5'-CATTCAGAGTCCTGCCCTCATTATT-3' \\
\hline
\end{tabular}

Table 2: Prevalence of virulence genes in UPEC isolates

\begin{tabular}{lcccc}
\hline Gene & \multicolumn{2}{c}{ Herb-resistant isolates } & \multicolumn{2}{l}{ Herb- susceptible isolates } \\
& No. of isolates & Percentage & No. of isolates & Percentage \\
\cline { 2 - 5 } & 5 & & & 6.9 \\
\hline Aer & 12 & 27.8 & 18 & 20.7 \\
papC & 4 & 66.7 & 10 & 11.5 \\
hly & 15 & 22.2 & 35 & 40.2 \\
\hline
\end{tabular}


Table 3: Adherence assay of E. coli; a $\mathrm{p}<0.05$ compared with resistant $E$. coli

\begin{tabular}{|c|c|c|c|c|}
\hline \multirow{2}{*}{$\begin{array}{c}\text { Time } \\
(\mathrm{min})\end{array}$} & \multicolumn{2}{|c|}{ Resistant E. coli } & \multicolumn{2}{c|}{ Susceptible E. coli } \\
\cline { 2 - 5 } & Adherence ratio $(\%)$ & Adherence index & Adherence ratio $(\%)$ & Adherence index \\
\hline 15 & $17.3 \pm 2.1$ & $4.4 \pm 0.5$ & $8.3 \pm 0.8^{\mathrm{a}}$ & $2.9 \pm 0.2^{\mathrm{a}}$ \\
\hline 30 & $54.8 \pm 5.1$ & $17.8 \pm 1.6$ & $28.7 \pm 2.9^{\mathrm{a}}$ & $10.2 \pm 1.1^{\mathrm{a}}$ \\
\hline 60 & $58.3 \pm 5.9$ & $19.2 \pm 1.8$ & $29.4 \pm 3.0^{\mathrm{a}}$ & $11.3 \pm 1.3^{\mathrm{a}}$ \\
\hline 120 & $63.5 \pm 6.7$ & $22.4 \pm 2.1$ & $28.9 \pm 2.4^{\mathrm{a}}$ & $10.9 \pm 1.2^{\mathrm{a}}$ \\
\hline 180 & $60.1 \pm 5.8$ & $20.3 \pm 2.0$ & $26.7 \pm 2.5^{\mathrm{a}}$ & $9.8 \pm 0.9^{\mathrm{a}}$ \\
\hline
\end{tabular}

\section{Results}

\section{Susceptibility test}

Among the 105 UPEC isolates, 18 (17.4\%) was resistant to the herbal concoction.

The MIC value of herbal solution was $0.1 \mathrm{~g} / \mathrm{ml}$ for susceptible E. coli. Among the 87, susceptible strains, 6 (6.9\%) caused clearing of blood agar around areas of bacterial growth. Among the 18, resistant isolates, the number is $3(16.7 \%)$.

Table 2 summarizes the content of virulence genes for UPEC isolates. The genes occurred in the majority of herb-resistant isolates, with Cnf1 and papC occurring in $\geq 66.7 \%$ of isolates, except for hly, and Aer, which occurred in $22.2 \%$ and $27.8 \%$ of strains respectively. Only one gene (Cnf1) occurred in $>40 \%$, of herb-susceptible isolates. Other genes were also found in susceptible isolates: papC (20.7\%), hly (11.5\%), and Aer (6.9\%). Figure 1 shows the representative examples of the comparative PCR analysis of herb-resistant and herb-susceptible strains.

At day 5, cell growth was observed around the sample pieces. At day 10, the regular pattern of urothelial cells can be noticed. Most of the cells were spindle shaped. At day 15, cells lush, densely covered the surface of the medium. At day 20, urothelial cells in KSFM grew as closely packed cobblestone-like colonies (Figure 2).

Light microscopy demonstrated cell structures were observed as well in specimens. Hematoxylin staining confirmed that all the specimens were normal and no dysplasia, or tumoral cells were recorded. Representative results are shown in Fig.3. Immuno-labelling intensity in all cells was similar. No difference in the immuno-labelling was recorded. The labelling was often slightly granular. No difference in labelling intensity was recorded among all cells (Figure 3).

Light microscopy and immunochemical investigations demonstrated the normal pelvic transitional epithelial cells cultured.

The role of herbal solution on the adhesion to human uroepithelial cells was evaluated. The adherence of strains in both groups increased at 30 min time point and reached the peak at 60 (Susceptible E. coli) or $120 \mathrm{~min}$ (Resistant E. coli) time point. The adhesion of the susceptible bacteria to human uroepithelial cells was significantly lower compared with that of the resistant E. coli (Table 3).

\section{Discussion}

The convenience of use of Chinese herbs is well recognized. However, increased prescription of Chinese herbs for common infections such as UTIs will facilitate the emergence of resistance, and promote the emergence of Chinese herb-resistant strains. Although clinical strains of UPEC resistance to Chinese herbs have been isolated in our previous study, the adherent ability and expression of virulence genes between resistant and susceptible isolates have not to our knowledge been compared before. Since Chinese herbs are currently used to UTIs, we feel that it is appropriate to develop a stronger understanding of the interaction between Chinese herb-resistance and changes in virulence factor expression. 
In this study, we have compared the adherent ability and genetic profiles of resistant and susceptible strains.
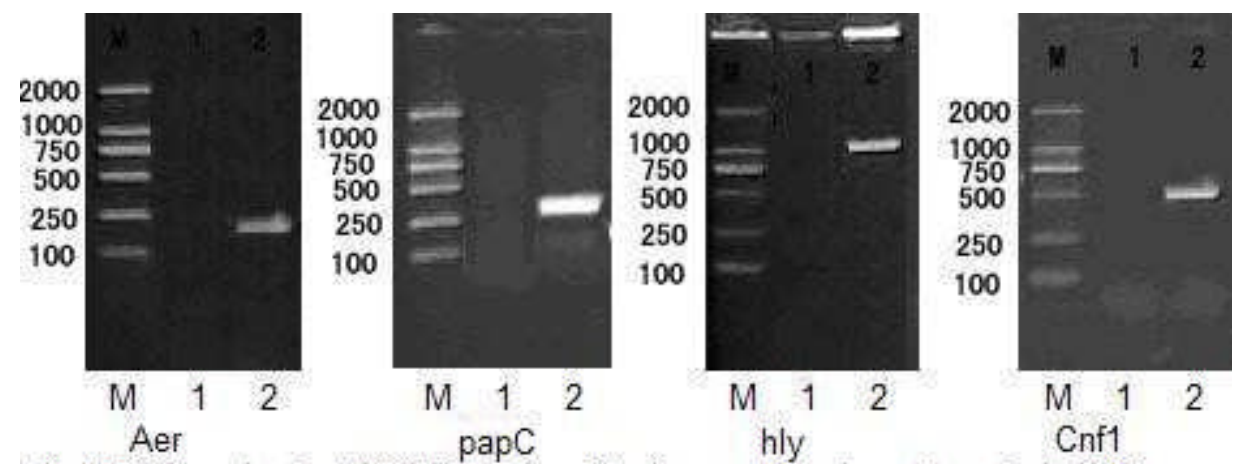

Fig. 1 PCR analysis of UPEC strains. Strains were analyzed by single-PCR approaches. The herb-resistant strains were positive for Aer, papC, hly and Cnf1. M, Marker; 1 , herb-susceptible strains; 2 , herb-resistant strains.

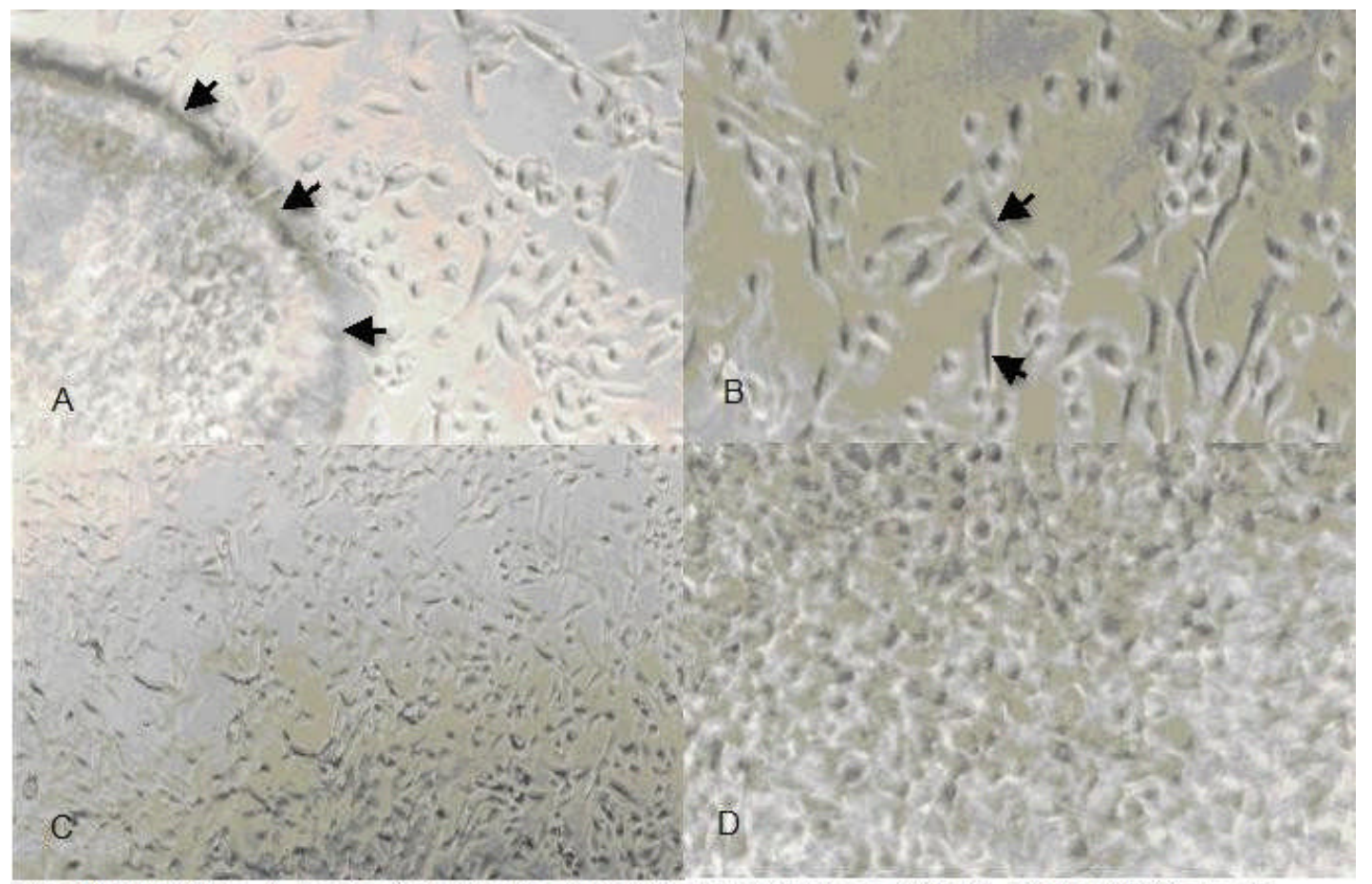

Fig. 2 Cell culture. A. day 5. Cell growth around the sample piece (Arrow). B. day 10. Cells are spindle shaped (Arrow). C. day 15. Cells densely covered the surface of the medium. D. day 20. Cells grew and exhibited an epithelial cobblestone appearance.

In this research, the urothelial cells were derived from Chinese people, in whom, the surface of urothelial cells are almost with P-blood group antigens. Hence, E. coli with P fimbriae will show the combined effects of adhesion with these antigens. Thus, human urothelial cells obtained are suitable for adhesion study. Normal human urothelial cells are close to the micro-environment in vivo and can truly reflect the process of UTIs. 
The data presented in this study reveal a considerable difference between Chinese herb-resistant and herb-susceptible uropathogenic $E$. coli clinical isolated. The increase in adhesion of resistant E. coli culturing in herbal solution can theoretically be caused by several mechanisms, such as the maintenance of fimbriae, which need further investigations.

The data presented in this study also reveal a considerable difference between Chinese herb-resistant and herb-susceptible UPEC, clinical isolated. This study shows that Chinese herb-resistant UPEC isolates have a higher prevalence of carrying virulence genes than susceptible isolates.

The adhesin gene, papC, presents frequency of $66.7 \%$ in resistant isolates and $20.7 \%$ in susceptible ones. Since the binding to the host cells is a key factor for development of infection, the expression of adhesin confers advantages to pathogens (Antão et al., 2009). hly, which contained in a higher number of resistant strains, is associated with higher clinical severity in UTI patients (Marrs et al., 2005). hly can inactivate the serine/threonine kinase Akt, which plays an essential role in host cell cycle progression, metabolism, survival, and inflammatory signaling pathways (Wiles et al., 2008a).

Production of toxins, such as cnf1, causes tissue damage, facilitating bacterial dissemination, releasing of host nutrients, and may also modulate host signaling pathways (Wiles et al., 2008b; Smith et al., 2008). The frequency of cnf1 expression is extremely higher in resistant strains, which indicate higher degree of virulence.

In summary, Chinese herb-resistant uropathogenic E. coli isolates that are haemolytic and have Aer, papC, hly, Cnf1 genes are more able to be uro-pathogenic and adherent. Furthermore, the resistance itself may be a virulence factor that allows for the survival of a bacterium within the urinary tract of patients.

As Chinese herbs use in UTIs drives up the frequency of Chinese herb-resistant isolates of UPEC, clinicians will see a modification in the patterns of UTIs accompanied by changes in the expression of specific UPEC virulence factors.

\section{Acknowledgment}

All authors in the article have made significant contributions. In addition, they are in agreement with the content of the manuscript. There is no conflict of interest. The research was funded by the Research Fund for the Doctoral Program of Higher Education of China (No. 20102227120004), Administration of Traditional Chinese Medicine of Jilin Province (No. 2010-009), and Natural Science Foundation of Jilin Province (No. 201015207), Jilin Provincial Education Department (No. 2011- 440).

\section{References}

1. Antão E.M, Wieler L.H, Ewers C. 2009. 'Adhesive Threads of Extra-intestinal Pathogenic Escherichia coli.' Gut Pathog 1: 22.

2. Beachey E.H. 1981. 'Bacterial adherence: adhesin-receptor interactions mediating the attachment of bacteria to mucosal surface.' J Infect Dis 143: 325-345.

3. Forbes B.A, Sahm D.F, Weissfeld A.S. 1998. Bailey and Scott's Diagnostic Microbiology. St Louis, MO: Mosby.

4. Hutton, K.A, Trejdosiewicz, L.K, Thomas, D.F, Southgate J. 1993. 'Urothelial tissue culture for bladder reconstruction: an experimental study.' J Urol 150: 721-725.

5. Johnson J.R, Stell AL. 2000. 'Extended virulence genotypes of Escherichia coli strains from patients with urosepsis in relation to phylogeny and host compromise.' J Infect Dis 181: 261-272.

6. Maidment C, Dyson A, Haysome I. 2006. 'A study into the anti-microbial effects of cloves (Syzgium aromaticum) and cinnamon (Cinnamomum zeylanicum) using disc- diffusion assay.' Nutr Food Sci 36: 225-230.

7. Marrs C.F, Zhang L, Foxman B. 2005. Escherichia coli mediated urinary tract infections: are there distinct uropathogenic E. coli (UPEC) pathotypes? FEMS Microbiol Lett 252: 183-190.

8. Smith Y.C, Rasmussen S.B, Grande K.K, Conran R.M, O'Brien A.D. 2008. Hemolysin of uropathogenic Escherichia coli evokes extensive shedding of the uroepithelium and hemorrhage in bladder tissue within the first 24 hours after intraurethral inoculation of mice. Infect Immun 76: $2978-2990$.

9. Southgate J, Hutton K.A, Thomas D.F, Trejdosiewicz LK. 1994. Normal human urothelial cells in vitro: proliferation and induction of stratification. Lab Invest 71: 583-594.

10. Southgate J, Masters J.R, Trejdosiewicz L.K., 2002. Culture of Human Urothelium. In 'Culture of Epithelial Cells.' Freshney R.I and 
Tong et al., Okmen and Turkcan Afr J Tradit Complement Altern Med. (2014) 11(1):109-115 http://dx.doi.org/10.4314/ajtcam.v11i1.16

Freshney M.G. New York: Wiley.

11. Tong Y, Jing Y, Zhao D, Zhang L, Zeng S. 2011a. Fluoroquinolone- resistant uncomplicated urinary tract infections, Chinese herbal medicine may provide help. Afr J Tradit Complement Altern Med 8: S108-S114.

12. Tong Y, Wu Q, Zhao D, Liu Y, Cao M, Zhang L, Zeng S. 2011b. 'Effects OF Chinese Herbs on the Hem-agglutination and Adhesion of EscharIchia Coli Strain In Vitro.' Afr J Tradit Complement Altern Med 8: 82-87.

13. Wiles T.J, Dhakal B.K, Eto D.S, Mulvey M.A. 2008a. 'Inactivation of host, Akt/protein kinase B signaling by bacterial pore-forming toxins. Mol Biol Cell 19: 1427-1438.

14. Wiles T.J, Kulesus R.R, Mulvey M.A. 2008b. 'Origins and virulence Mechanisms of Uropathogenic Escherichia coli.' Exp Mol Pathol 85: 11-19. 